\title{
Emotional reactions in women attending a UK colposcopy clinic
}

\author{
D H Gath, N Hallam, L Mynors-Wallis, A Day, S A K Bond
}

\begin{abstract}
Study objective - To assess the emotional responses of women attending a colposcopy clinic for investigation of an abnormal cervical smear, and to elicit the women's views on the screening service and colposcopy clinic.

Design - Over 12 months all new attenders at a colposcopy clinic were invited to join the study. They were assessed psychiatrically four weeks before their first clinic appointment, and four weeks and 32 weeks after their first clinic appointment. Setting - Colposcopy clinic, John Radcliffe Hospital, Oxford.

Patients - Of 114 women attending the colposcopy clinic for investigation of an abnormal cervical smear, 102 agreed to enter the study.

Measurements - Psychiatric symptoms were assessed with a standardised psychiatric interview, the present state examination; and with four self rated mood scales:- the general health questionnaire, the Beck depression inventory, the Leeds depression scale, and the Leeds anxiety scale.
\end{abstract}

Main results - On all these measures, in the whole patient group, psychiatric morbidity was found to be transient and relatively minor. Thus ratings on the present state examination were not significantly higher than the rate found in a community sample of 520 women in Oxford, while on the four self rated mood scales, mean total scores were lower than the cut off value used to distinguish cases. Patient satisfaction with the colposcopy services was generally high but there was some dissatisfaction with delays.

Conclusions - After an abnormal cervical smear, further investigation by colposcopy is generally associated with low levels of anxiety and depression.

Department of

Psychiatry,

University of Oxford,

Warneford Hospital,

Oxford OX3 7JX

D H Gath

L Mynors-Wallis

A Day

S A K Bond

Colposcopy Unit, John Radcliffe

Hospital (Maternity), Oxford OX3 9DU

N Hallam

Correspondence to:

Dr D H Gath.

Accepted for publication April 1994

\section{(F Epidemiol Community Health 1995;49:79-83)}

It has been reported that health screening programmes may cause emotional responses such as anxiety and depression, even when the findings are normal. ${ }^{1}$ When screening detects a possible abnormality requiring further investigation, it might be expected that the patient would be particularly vulnerable to emotional symptoms. A leading medical journal emphasised this point in an editorial - "a positive result in any screening test is invariably received with negative feelings". ${ }^{2}$
Studies of cervical screening suggest that levels of emotional distress are high in women with an abnormal result. ${ }^{3}$ It seems, however, that no study has used standardised methods to determine the nature, severity, frequency, and duration of emotional disturbance in women awaiting and then receiving colposcopy after an abnormal cervical smear.

Our overall purpose was to study a group of women attending a colposcopy clinic for investigation of an abnormal cervical smear. The main aims were:

(i) To use standardised psychiatric measures (both interview and self report measures) to assess the frequency, nature, severity and duration of emotional symptoms in these women;

(ii) To elicit the women's views on the screening service and colposcopy clinic.

\section{Methods}

The study was based on a consecutive series of women attending the colposcopy clinic at the John Radcliffe Hospital, Oxford, over a 12 month period. All the women had been found to have an abnormal cervical smear either at routine screening or at follow up of a previously inconclusive smear. None had made a previous attendance at a colposcopy clinic.

The women were interviewed on three occasions. The first interview took place four weeks before their first clinic appointment. (Careful consideration was given to the possibility of interviewing the women soon after they received news of their abnormal smear, but this timing was not adopted because it might have been too stressful for the women.) The second interview was conducted four weeks after the first clinic appointment and the third 36 weeks after the first clinic appointment. The timing of the third interview was chosen because all patients would be likely to have completed their treatment by then.

Assessments were carried out in the women's homes by a woman interviewer with extensive experience of interviewing women with psychiatric and gynaecological problems.

Psychiatric symptoms were assessed in three ways as follows:

(i) At the first assessment, the women were asked to recall any emotions they had felt on first learning about the abnormal smear result.

(ii) At all three assessments a standardised psychiatric interview, the 9th edition of the present state examination (PSE), ${ }^{5}$ was carried out.

(iii) At all three assessments, the women completed four self report questionnaires designed to measure psychiatric symptoms - the 28 item general health questionnaire ${ }^{6}$ the Beck 
depression inventory ${ }^{7}$ the Leeds depression and anxiety scale ${ }^{8}$ and the Spielberger statetrait anxiety inventory. ${ }^{9}$

At each assessment the women also completed the social adjustment scale, ${ }^{10}$ which measures general social functioning, and the dyadic adjustment scale ${ }^{11}$ which measures marital function. At the first assessment all the women completed the Eysenck personality inventory, ${ }^{12}$ which measures personality traits.

Each assessment included a semistructured interview about gynaecological health and psychosexual functioning. Questions were also asked about the experience of attending the clinic.

\section{ANALYSIS OF DATA}

The data were analysed with the Statistical Package for the Social Sciences, ${ }^{13}$ using $\chi^{2}$, and two-tailed $t$ tests as appropriate. Certain continuous variables were not normally distributed, but logarithmic transformations enabled parametric statistical tests to be carried out.

ETHICAL APPROVAL

This study was approved by the local Psychiatric Research Ethics Committee.

\section{Results}

A total of 114 women were eligible for the study, of whom $102(90 \%)$ agreed to be seen at the first assessment, 99 at the second assessment, and 96 at the third assessment. Of the 102 women, $55(54 \%)$ were in the age range 18-30 years, $34(33 \%)$ in the range $31-40$ years, and the remaining $13(13 \%)$ in the range 41-60 years. The mean age was $31 \cdot 3$ years. The marital status of the women was as follows: married $53(52 \%)$, single $31(30 \%)$, divorced/ separated $14(14 \%)$, and widowed $4(4 \%)$. The social class distribution of the women did not differ significantly from that of women living in Oxford.
In the sample as a whole, the mean (SD) neuroticism score on the Eysenck personality inventory was $10.98(5.4)$, which does not differ significantly from the mean for the general population of women.

\section{THE WOMEN'S INITIAL RESPONSE TO AN} ABNORMAL SMEAR

At the first assessment, most women reported that the emotional impact of the abnormal smear had been severe in the first week after notification. Thus, in answer to the general question, "What was your reaction to learning about the abnormal smear?" $52(51 \%)$ women volunteered the words "shock", "panic" or "horror". In answer to specific questions about their mood in the first week after notification, $92(90 \%)$ of the women reported fear and worry; 68 (67\%) depressed mood; 66 (65\%) pessimism; $45(44 \%)$ poor concentration; 44 (43\%) irritability; 34 (33\%) lack of usual interests; $30(29 \%)$ sleep disturbance; and 22 $(22 \%)$ headaches. The main fears were of cancer and of needing to be admitted to hospital.

EMOTIONAL SYMPTOMS AS MEASURED WITH THE PSE - TOTAL PATIENT SAMPLE

The PSE findings for the total patient sample at assessments 1,2, and 3 are shown in table 1. The table also gives comparative data for a community sample of 520 women from two local general practices. ${ }^{14}$ The two samples are not strictly comparable because the community women were aged 35-59 years and most of the colposcopy women were aged under 40 years.

\section{PSE total scores}

The PSE total score gives an overall measure of psychiatric morbidity for each patient. As shown in table 1 , the PSE mean total score of the colposcopy sample fell from 4.08 at assessment 1 to 3.49 at assessment 2 , and to 2.55 at assessment 3 . Although the mean total score was significantly lower at assessment 3

Table 1 Present state examination (PSE) findings - frequency of emotional symptoms

\begin{tabular}{|c|c|c|c|c|}
\hline & $\begin{array}{l}\text { Assessment } 1 \\
\text { (4 wk before } \\
\text { first clinic) }\end{array}$ & $\begin{array}{l}\text { Assessment } 2 \\
\text { (4 wk after } \\
\text { first clinic) }\end{array}$ & $\begin{array}{l}\text { Assessment } 3 \\
\text { (8 mth after } \\
\text { first clinic) }\end{array}$ & $\begin{array}{l}\text { Oxford } \\
\text { community } \\
\text { sample }\end{array}$ \\
\hline Patient numbers & 102 & 99 & 96 & 520 \\
\hline $\begin{array}{l}\text { PSE mean total score } \\
\text { (SD) } \\
\text { Range }\end{array}$ & $\begin{array}{l}4 \cdot 08 \\
(5 \cdot 9) \\
0-27\end{array}$ & $\begin{array}{l}3.49 \\
(5 \cdot 9) \\
0-28\end{array}$ & $\begin{array}{l}2 \cdot 55^{*} \\
(5 \cdot 1) \\
0-28\end{array}$ & $\begin{array}{l}2 \cdot 76 \\
(4 \cdot 9) \\
0-28\end{array}$ \\
\hline $\begin{array}{l}\text { PSE syndromes (no (\%)): } \\
\text { Situational anxiety } \\
\text { Tension } \\
\text { Worry } \\
\text { Somatic features of depression } \\
\text { Irritability } \\
\text { Social unease } \\
\text { Impaired concentration } \\
\text { General anxiety }\end{array}$ & $\begin{array}{l}40(39) \\
37(36) \\
37(36) \\
23(23) \\
21(21) \\
21(21) \\
15(15) \\
14(14)\end{array}$ & $\begin{array}{l}29(29) \\
26(26) \\
30(30) \\
21(21) \\
15(15) \\
14(14) \\
15(15) \\
15(15)\end{array}$ & $\begin{array}{l}24(25) \dagger \\
20(21) \ddagger \\
20(21) \dagger \\
12(13) \\
16(17) \dagger \\
10(10) \dagger \\
11(11) \dagger \\
7(7) \dagger\end{array}$ & $\begin{array}{l}71(14) \oint \\
119(23) \oint \\
165(32) \\
71(14) 9 \\
72(14) \\
70(14) \\
30(6) \oint \\
56(11)\end{array}$ \\
\hline $\begin{array}{l}\text { PSE case status: } \\
\text { Non-cases } \\
\text { Cases }\end{array}$ & $\begin{array}{l}91(89) \\
11(11)\end{array}$ & $\begin{array}{l}86(87) \\
13(13)\end{array}$ & $\begin{array}{r}91(95) \\
5 \quad(5)\end{array}$ & $\begin{array}{r}470(90) \\
50(10) \\
\end{array}$ \\
\hline
\end{tabular}


Table 2 Psychological and social morbidity assessed with self report questionnaires

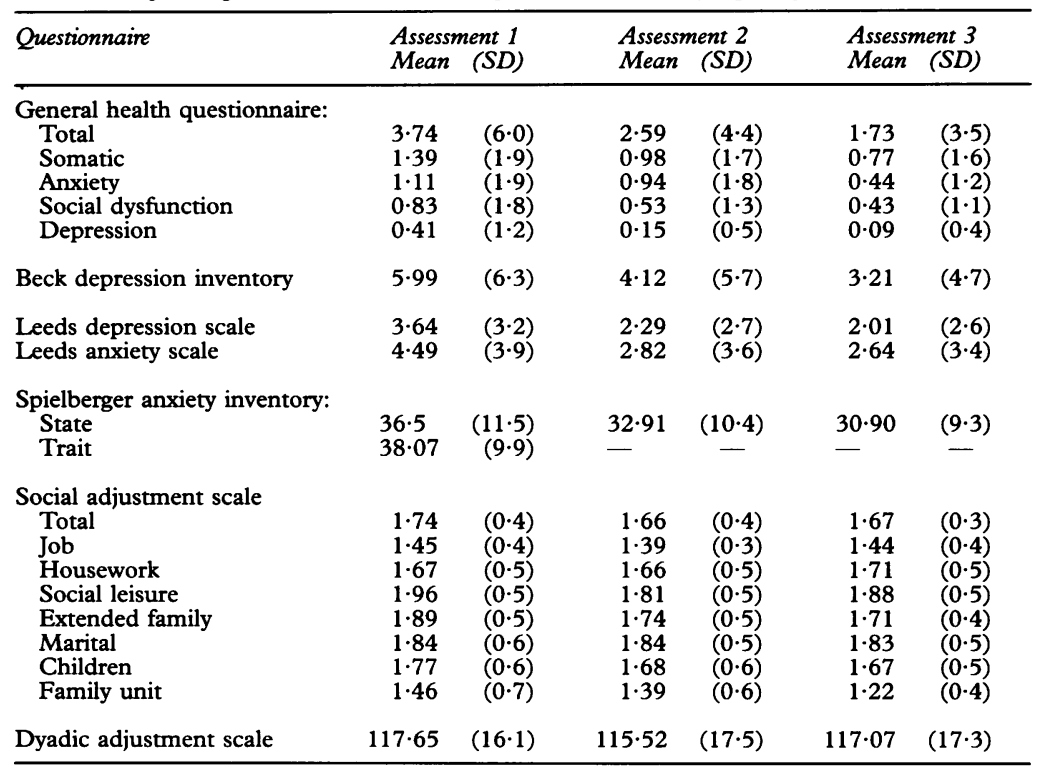

than at assessments 1 and 2 , none of these values differed significantly from the mean total score of the women in the community sample.

\section{Psychiatric syndromes}

Responses to individual questions on the PSE can be combined to identify psychiatric syndromes. Table 1 shows the distributions of the eight most frequent syndromes over the three assessments. From assessment 1 to assessment 3 , there was a statistically significant decrease in the frequency of all syndromes except somatic features of depression. By comparison with the community sample, at assessment 1 the colposcopy women were significantly more likely to be suffering from situational anxiety, tension, impaired concentration, somatic features of depression.

\section{PSE case status}

PSE data can be analysed to determine whether a person's symptoms are sufficiently numerous or severe to indicate "psychiatric case" status. As shown in table 1, the proportions of PSE cases in the colposcopy sample were $11 \%, 13 \%$, and $5 \%$ respectively at the three assessments (as against $10 \%$ in the Oxford community sample).

At assessment 1, two factors were significantly associated with PSE case status; namely living alone (cases 63\%, non-cases $\left.25 \%, \chi^{2}=5 \cdot 23(\mathrm{df}=1) \mathrm{p}<0.05\right)$, and having previously seen a psychiatrist (cases $36 \%$, noncases $\left.8 \% ; \chi^{2}=5.67(\mathrm{df}=1) \mathrm{p}<0.02\right)$. Examples of factors not associated with PSE case status were as follows: (i) clinic factors: the current smear being the first abnormal smear, and length of wait between notification and first appointment; (ii) social factors: not having a confidant, not having had children, not being in paid employment, and adverse life events.

After assessment 3, inspection of clinic case notes showed that $14(14 \%)$ women had received no gynaecological treatment, while two $(2 \%)$ had received cryotherapy, 39 (38\%) laser treatment, 17 (17\%) loop excision of the transformation zone, 19 (19\%) knife cone biopsy, seven $(7 \%)$ diathermy under general anaesthetic, and three (3\%) hysterectomy. There was no association between psychiatric case status and any of these treatments.

EMOTIONAL SYMPTOMS AS MEASURED WITH SELF REPORT QUESTIONNAIRES - TOTAL PATIENT SAMPLE

The findings from the self report questionnaires at assessments 1, 2, and 3 for the total patient sample are shown in table 2 . At all three assessments the mean total score on the 28 item general health questionnaire was under five, the threshold for probable psychiatric morbidity. Similarly, scores at all three assessments were in the normal range on the Beck depression inventory (cut off score for mild depression is 14 and above), the Leeds depression and anxiety scale (cut off score is above 6 ), and the Spielberger anxiety inventory. On the social adjustment scale, social functioning was not adversely affected over the three assessments. On the Dyadic adjustment scale, the quality of the relationship with the husband or partner did not change between assessments 1 and 3 .

As reported above, a subgroup of 52 women used the words "shock", "panic", or "horror" to characterise their response to learning of the abnormal smear. For convenience this group will be referred to as the "shock" subgroup. As shown in table 3, compared with the other 50 patients, at assessment 1 this subgroup had significantly higher mean total scores on the PSE, the general health questionnaire, the Beck depression inventory, the Leeds depression scale, the Leeds anxiety scale, the Spielberger state anxiety inventory, and the neuroticism dimension of the Eysenck personality inventory.

Table 3 Psychological morbidity (mean total score) at assessment 1 of patients who described their response as "shock"

\begin{tabular}{|c|c|c|c|c|c|c|c|c|c|}
\hline & \multicolumn{2}{|c|}{$\begin{array}{l}\text { “Shock" subgroup } \\
(n=52)\end{array}$} & \multicolumn{2}{|c|}{$\begin{array}{l}\text { Other patients } \\
(n=50)\end{array}$} & \multicolumn{5}{|c|}{ Analysis carried out on logarithmically transformed data } \\
\hline & Mean & $(S D)$ & Mean & $(S D)$ & $t$ value & $d f^{*}$ & p value & dift & $(95 \% C I)$ \\
\hline $\begin{array}{l}\text { Present state examination } \\
\text { General health questionnaire } \\
\text { Beck depression inventory } \\
\text { Leeds depression scale } \\
\text { Leeds anxiety scale } \\
\text { Spielberger state anxiety inventory } \\
\text { Neuroticism (Eysenck personality } \\
\text { inventory) }\end{array}$ & $\begin{array}{r}5 \cdot 38 \\
5 \cdot 43 \\
8 \cdot 17 \\
4 \cdot 35 \\
6 \cdot 00 \\
40 \cdot 67 \\
12 \cdot 28\end{array}$ & $\begin{array}{r}(6 \cdot 2) \\
(7 \cdot 1) \\
(7 \cdot 2) \\
(3 \cdot 5) \\
(3 \cdot 9) \\
(11 \cdot 4) \\
(5 \cdot 4)\end{array}$ & $\begin{array}{r}2 \cdot 72 \\
2.04 \\
3.98 \\
2.94 \\
3.02 \\
32 \cdot 33 \\
9.76\end{array}$ & $\begin{array}{r}(5 \cdot 4) \\
(4 \cdot 2) \\
(4 \cdot 6) \\
(2 \cdot 9) \\
(3 \cdot 2) \\
(10 \cdot 2) \\
(5 \cdot 0)\end{array}$ & $\begin{array}{l}3 \cdot 01 \\
3 \cdot 76 \\
3 \cdot 74 \\
2 \cdot 23 \\
3 \cdot 99 \\
4 \cdot 07 \\
2 \cdot 36 \ddagger\end{array}$ & $\begin{array}{r}100 \\
96 \\
94 \\
95 \\
95 \\
94 \\
95\end{array}$ & $\begin{array}{l}0.003 \\
0.000 \\
0.000 \\
0.028 \\
0.000 \\
0.000 \\
0.02\end{array}$ & $\begin{array}{l}0 \cdot 279 \\
0 \cdot 313 \\
0 \cdot 306 \\
0 \cdot 152 \\
0 \cdot 268 \\
0 \cdot 097 \\
2 \cdot 517\end{array}$ & $\begin{array}{l}(0.096,0.462) \\
(0.478,0.148) \\
(0.468,0.143) \\
(0.287,0.017) \\
(0.401,0.135) \\
(0.145,0.05) \\
(4 \cdot 63,0.404)\end{array}$ \\
\hline
\end{tabular}

* = degrees of freedom;

$\dagger=$ difference between means (logarithmically transformed);

$\ddagger=$ normally distributed, so not logarithmically transformed 
At assessment 2, the "shock" subgroup still had significantly higher mean total scores on the Leeds anxiety scale (mean (SD) $3.94,(4 \cdot 3)$ $v 1.63(2.0) \mathrm{t}=2.75(\mathrm{df}=93) \mathrm{p}=0.007$; difference between means (logarithmically transformed) $=0.211,95 \% \mathrm{CI}=0.363,0.059)$ and the Spielberger state anxiety inventory $(35 \cdot 14$ $(12 \cdot 2) v 30.42(7 \cdot 4) \mathrm{t}=2.07(\mathrm{df}=93) \mathrm{p}=$ 0.042 ; difference between means (logarithmically transformed) $=0.0503,95 \% \mathrm{CI}=$ $0.099,0.001$ ).

At assessment 3, there were two small significant findings - the "shock" subgroup had significantly higher mean total scores on the Leeds depression scale $(2.71$ (3.1) $v 1.28(1 \cdot 8)$ $\mathrm{t}=2.44(\mathrm{df}=86) \mathrm{p}=0.017$; difference between means (logarithmically transformed) $=0 \cdot 1742$, $95 \% \mathrm{CI}=0.316,0.032)$ and the Leeds anxiety scale $(3.58(4 \cdot 1) v 1.68(2 \cdot 2) \mathrm{t}=2.21(\mathrm{df}=87)$ $\mathrm{p}=0.03$; difference between means (logarithmically transformed) $=0 \cdot 172,95 \% \mathrm{CI}=$ $0 \cdot 327,0 \cdot 017)$.

\section{PSYCHOSEXUAL FUNCTIONING}

At the first assessment, in answer to an enquiry about the frequency of sexual intercourse after receiving the abnormal smear result, the responses were as follows: increased frequency 1 woman ( $1 \%$ of those with a sexual partner), no change 50 (56\%), decreased frequency 38 (43\%). Examples of the women's explanations for this decrease were: "it didn't feel right with a growth in me" (8 women), "it might make things worse" ( 8 women), or "I felt unclean" (8 women). At the first assessment, in answer to an enquiry about enjoyment of sexual intercourse, the responses were as follows: increased enjoyment 1 woman ( $1 \%)$, no change $55(63 \%)$, decreased enjoyment 31 (36\%); psychological reasons were frequently reported, for example "I couldn't get the result out of my mind" (14 women). At the first assessment, 24 women $(26 \%)$ reported deterioration in their sexual relationship as a result of the abnormal smear result while the rest reported no change. Three women (3\%) reported an increased interest in sex as a result of the abnormal smear compared with $56(60 \%)$ who reported no change and $35(37 \%)$ who reported a decreased interest in sex. By assessment 3, however, when asked to compare the frequency of sexual intercourse with the two months before being asked to go to the colposcopy clinic, the corresponding proportions were considerably altered: increased frequency was reported by 25 women ( $29 \%$ of those with a sexual partner), no change by $44(52 \%)$, and decreased frequency by $16(19 \%)$. The women were also asked whether there had been any change in their enjoyment of sexual intercourse compared with the two months before they were asked to attend the colposcopy clinic. Increased enjoyment was reported by 21 women $(27 \%)$; no change by $49(62 \%)$; and decreased enjoyment by $9(11 \%)$. At assessment 3 the women were asked if their sexual relationship had altered as a result of the treatment. Seventeen women $(22 \%)$ reported an improved sexual relationship, no change was reported by $57(74 \%)$, and deterioration by $3(4 \%)$. The women were also asked if there had been any change in their interest in sex as a result of the treatment. Sixteen women $(21 \%)$ reported increased interest, $55(71 \%)$ no change, and $6(8 \%)$ reduced interest.

\section{THE WOMEN'S BELIEFS ABOUT THE CAUSES OF} ABNORMAL SMEARS

At the first assessment the women were asked to suggest possible causes for their abnormal smear. The main responses were: chance (29 (28\%) women); youthful ignorance/early sex (15 (15\%)), current or former partner(s) (12 $(12 \%))$, oral contraception $(9(9 \%))$, pregnancy $(7(7 \%))$, previous wart virus infection (4 (4\%)); no particular cause (11 (11\%)). Thirteen women $(13 \%)$ wished to stress that they had not been promiscuous.

THE WOMEN'S COMMENTS ON THE SCREENING SERVICE AND THE COLPOSCOPY CLINIC

About six weeks (mean 5.9 weeks, range 1-22 weeks) had elapsed between the smear being taken and the result being notified to the GP. The women then had to wait about three months (mean 12.6 weeks, range 6-24 weeks) for their first clinic attendance, with the knowledge that the smear was abnormal. At the first assessment the women were asked how they felt about this wait; about a quarter said they felt reassured by the wait as indicating that the abnormality could not be too serious; another quarter, however, were angry at the delay.

At the end of the first assessment, 48 (47\%) women said that they felt a need for more information about screening at the time of the initial smear; such information should be both verbal and written. On receiving notification of the abnormal smear, the women felt a need for information of three main types:

(i) What did the findings mean? Were the cells cancerous? How had the abnormality developed? What was the prognosis?

(ii) What was a colposcopy?

(iii) What would happen at the clinic? When would treatment occur? What would be the after effects? When would the results be available?

Other concerns were about future pregnancies, and whether male doctors and/or medical students would be present at the examination.

The experience of colposcopy varied. At assessment 2 , on being asked "What did you feel about the colposcopy procedures?" 49 (49\%) of the women had no adverse comments, but 50 (51\%) reported pain, embarrassment, shock, or distress. As many as 96 women (97\%) were satisfied with the colposcopist's explanation before colposcopy, and $67(68 \%)$ were satisfied with the explanation of the findings from colposcopy. At assessment 3, in response to the open question, "Looking back over the last year, what do you feel about the colposcopy clinic?" $52(54 \%)$ of the women said they were very pleased with the clinic service as a whole, 
31 women were pleased overall but were disconcerted by the wait between the smear result and the first clinic visit, while 13 again emphasised the discomfort of the procedure.

After attending the clinic and completing treatment, most women (85\%) commented that a detailed and illustrated pamphlet should be provided before the first clinic attendance. The pamphlet should explain the possible treatments and their after effects, the length of time before receiving results, the necessity for regular follow up smears, and the implications of malignancy and chemotherapy.

\section{Discussion}

This study had two main aims. The first was to measure psychiatric morbidity in women attending a colposcopy clinic for investigation of an abnormal cervical smear. The second was to obtain women's views on the cervical screening service and the colposcopy clinic.

Two aspects of design and method are relevant to these aims. The first was that the sample of women in the study was likely to be representative of women attending the Oxford colposcopy clinic. Thus, the sample was a consecutive series of women attending the clinic. It was of adequate size $(n=102)$; and the numbers of women who declined to participate $(\mathrm{n}=$ 12), or who joined the study but dropped out (three at the second assessment and three at the third assessment) were low. The second aspect of method was that emotional symptoms were identified and measured with a range of standardised instruments, including both self rated scales and a psychiatric interview (PSE)).

In the sample as a whole levels of psychiatric morbidity were generally low. Thus, at all three assessments levels of emotional morbidity were no higher than the figures reported in the general population of women. At the first assessment, but not subsequently, four PSE syndromes were more frequent in the colposcopy group - namely situational anxiety, tension, impaired concentration, and somatic features of depression.

A subgroup of 52 patients used the words "shock", "panic", or "horror" to describe their initial reaction to news of the abnormal smear. In this subgroup, the PSE total scores were significantly higher at the first assessment, and diminished less over time than did the scores of the group not reporting this response.

This finding may not have major implications for the staff of the colposcopy clinic. For primary care physicians however, the findings may be more significant. Thus if a patient consults a general practitioner with complaints of panic after receiving notification of an abnormal smear, the GP may offer supportive counselling to prevent persistent anxiety and depression. While the complaint of panic is important, the GP should also consider providing supportive counselling for women who report other mood changes such as depression after notification of an abnormal smear. For most women, the counselling could consist of providing appropriate information, reassurance, and advice. This support could be provided by a GP or a trained nurse counsellor. This approach should be reinforced by an information sheet from the colposcopy clinic. If necessary, further support could be provided by a nurse counsellor at the colposcopy clinic.

In the whole sample two factors were found to be significantly associated with PSE case status - living alone and previous psychiatric contact. Both factors seem understandable in this context. About a third of the women with a sexual partner reported that their sexual functioning was impaired after they had been informed of the abnormal smear. This experience is not surprising because many of the women reported increased anxiety and depression at that stage. By the time of the final assessment, most women had recovered normal sexual functioning.

With regard to the screening service, about a quarter of the women were disturbed about the length of their wait for the first clinic attendance. About half the women felt the need for more information about screening at the time the smear was taken.

The interval between the taking of the cervical smear and the issue of the report has now been reduced to about two weeks in the Oxford district, and patients are usually seen at the colposcopy clinic within two weeks of referral. An information pamphlet ${ }^{15}$ is now sent with all new colposcopy appointments, and is available in many general practices and family planning clinics in this district. The pamphlet outlines the importance of an abnormal smear and describes what happens at the colposcopy clinic.

Warm thanks are expressed to Mr Mark Charnock, Consultant in Obstetrics and Gynaecology, Dr Valerie Casemore, clinical assistant in the colposcopy clinic, and the women who took part in the study.

We are grateful to Mrs Annie Goodall for her secretarial help. The project was funded by the Oxford Regional Health Authority and the Mental Health Foundation; we are most grateful for their support.

1 Marteau TM. Reducing the psychological costs. BMf 1990 301:26-8.

2 Marteau TM. Psychological costs of screening. BMf 1989; 299:527.

3 Posner T, Vessey M. Prevention of cervical cancer: the patient's view. London: King Edward's Hospital Fund for London, 1988 .

4 Quilliam S. Positive smear - the emotional issues and what can be done. Health Education fournal 1990;49:19-20.

5 Wing JK, Cooper JE, Sartorius N. The measurement and classification of psychiatric symptoms. London: Cambridge University Press, 1974.

6 Goldberg DP, Hillier VF. A scaled version of the General Health Questionnaire. Psych Med 1979;9:139-45.

7 Beck AT, Ward CH, Mendelson M, Mock J, Erbaugh J. An inventory for measuring depression. Arch Gen Psych 1961 4:561-71.

8 Snaith RP, Bridge GWK, Hamilton M. The Leeds scale for the self-assessment of anxiety and depression. $\mathrm{Br} F$ Psychiatry 1976;128:156-65.

9 Spielberger CD, Gorsuch RL, Lushene R. State-trait anxiety inventory manual. Paola Alto: Consulting Psychologists' Press, 1970.

10 Cooper P, Osborn M, Gath DH, Feggetter G. Evaluation of a modified self-report measure of social adjustment. $B$ of a modified self-report measuriatry $1982 ; 141: 68-75$.

11 Spanier GP. Measuring dyadic adjustment: new scales for assessing the quality of marriage and similar dyads. fournal assessing the quality of marriage and similar
of Marriage and Family 1976;38:15-28.

12 Eysenck HJ, Eysenck SBG. The Eysenck personality inventory. London: University of London Press, 1963.

13 Nie NH. Statistical Package for Social Sciences. McGrawHill: New York, 1983.

14 Gath D, Osborn M, Bungay G, Iles S, Day A, Bond A Passingham C. Psychiatric disorder and gynaecological symptoms in middle aged women: a community sample. BMF 1987;294:213-18.

15 Cervical Cytology Advisory Group, Oxfordshire Health Authority. Women's health; questions about colposcopy. Oxford: Oxford Regional Health Authority, 1991. 